\title{
HumanizaSUS: uma experiência de humanização e gestão da comunicação em organizações hospitalares
}

HumanizaSUS: an experience of humanization and communication management in hospital organizations

HumanizaSUS: una experiencia de humanización y gestión de la comunicación en organizaciones hospitalarias

\section{Daniel de Oliveira Figueiredo}

- Mestre em Comunicação pelo programa de pós-graduação em Comunicação da Universidade Estadual de Londrina (UEL)

- Graduado em Relações Públicas pela UEL

- Professor do Curso de Relações Públicas da Universidade Estadual de Londrina (UEL)

- Professor dos cursos de Relações Públicas e Jornalismo da UEL

- E-mail: daniel.of.uel@gmail.com

\section{Estefânia Salmória Badia}

- Aluna do Curso de Especialização em Gestão Contemporânea de Recursos Humanos na Universidade Estadual de Londrina (UEL)

- Graduada em Comunicação Social - Relações Públicas pela UEL

- Experiência profissional na área de Relações Públicas e Assessoria de Imprensa na prefeitura de Londrina (CMTU-LD)

- E-mail: esttefania@hotmail.com 


\section{Resumo}

O presente artigo é um estudo sobre a humanização no ambiente interno de hospitais. Apresenta, em um primeiro momento, uma abordagem sobre a complexidade do ser humano, expondo a importância da valorização de sua subjetividade. Após esse enfoque, explora-se o conceito de humanização e as implicações que esta produz tanto na relação funcionário-paciente, quanto na relação funcionário-funcionário. Para tal, explora-se a relação intrínseca que há entre a humanização e a comunicação. A fim de embasar a relação apresentada, é utilizado como exemplo o HumanizaSUS, presente no sistema de saúde do Brasil.

PALAVRAS-CHAVE: COMUNICAÇÃO • HUMANIZAÇÃO • SUBJETIVIDADE • ORGANIZAÇÃO HOSPITALAR

\section{Abstract}

This article is a study on humanization in the hospital indoor. It presents, at first, a discussion of the complexity of the human being, exposing the importance of the appreciation of their subjectivity. Following this approach, it explores the concept of humanization and the implications that this produces both in the employee-patient relationship, and in employee-employee relationship. To this end, it explores the intrinsic relationship that exists between humanization and communication. In order to base the relationship shown is used as an example the HumanizaSUS, present in the Brazilian health system.

KEYWORDS: COMMUNICATION • HUMANIZATION • SUBJECTIVITY • HOSPITAL ORGANIZATION

\section{Abstract}

Este artículo es un estudio sobre la humanización del ambiente interno de hospitales. Presenta, en un primer momento, un abordaje sobre la complejidad del ser humano, exponiendo la importancia de la valorización de su subjetividad. Después de ese enfoque, se explora el concepto de humanización y las implicaciones que esto produce tanto en la relación empleado-paciente, cuanto en la relación empleado-empleado. Para ello, se explora la relación intrínseca que existe entre la humanización y la comunicación. Con el fin de fundamentar la relación presentada, se utiliza como ejemplo el HumanizaSUS, presente en el actual sistema de salud del Brasil.

PALABRAS CLAVE: COMUNICACIÓN • HUMANIZACIÓN • SUBJETIVIDAD • ORGANIZACIÓN HOSPITALARIA 
É pungente, na sociedade contemporânea, a preocupação com as condições de vida e trabalho das pessoas, uma vez que são razão e obviedade da existência e organização da vida coletiva. A maneira como se organizou a realidade atual permite deflagrar as organizações como o local onde, prioritariamente nas dimensões sociais e econômicas, o ser humano encontrou no trabalho um espaço de desenvolvimento e partilha dos sentimentos de pertencimento e identificação.

A temática da humanização se tornou, nos parâmetros ambientais descritos, de fundamental relevância para o entendimento dos processos culturais e de relacionamento humano. A comunicação, dessa forma, recria seu significado e partilha a intenção de humanizar processos de interação, constituindo ambiente favorável ao desenvolvimento das condições básicas da vida, entre elas a saúde.

Não apenas preocupados com a saúde das pessoas, os processos de relacionamento internos de uma organização, potencializados pela dimensão interacional da comunicação, também permitem visualizar a estrutura organizacional macro como uma grande teia de relações que, quando estabelecidas, formam identidade e cultura. Assim, as organizações, formadas por pessoas e que têm o bem-estar destas como elemento constitutivo, pondo a saúde como um eixo central de suas atividades e de sua natureza, também se tornam escopo interessante de análise e apreciação.

Nesse contexto, o presente artigo apresenta uma discussão acerca das características do ser humano como ser sociável e de como as organizações contemporâneas são o espaço/ambiente no qual ele projeta suas características pessoais particulares, sofrendo influência de via contrária. Especificamente, se faz uma reflexão sobre as organizações hospitalares e o processo de humanização, em que a comunicação tem esforço privilegiado na emancipação da subjetividade humana.

\section{O SER HUMANO}

O ser humano é demasiado complexo para ser resumido a uma concepção simplista. Jean-François Chanlat (2009, p. 27-28) acredita que ele não pode ser entendido em uma visão fragmentada, como explica:

Numerosos são os que, ainda hoje, fecham o ser humano em esquemas redutores e que frequentemente têm a impressão simplória de ter captado a essência do ser humano. A realidade humana que encontramos na organização não poderá jamais ser reduzida a tais esquemas. Só uma concepção que procura apreender o ser humano na sua totalidade pode dele se aproximar sem, contudo, jamais o esgotar completamente. 
O autor descreve as diferentes dimensões pertencentes ao ser humano. Primeiro, é preciso compreendê-lo como um ser ao mesmo tempo genérico e singular. Apesar das distintas disciplinas que o estudam, o ser humano é uno enquanto espécie e enquanto indivíduo. Segundo Chanlat, ele sempre existe em um ser concreto - por exemplo, como adulto, criança, pai, mulher etc. Cada um existe de uma forma singular, numa situação, o que the confere sua especificidade.

Seus diferentes elementos são interligados, assim como sua natureza e sua cultura o abarcam e o transformam. "Toda pessoa tem assim ao mesmo tempo o genérico e o específico. $O$ estudo do fator humano nas organizações não pode, portanto, abstrair-se desta dupla dependência" (Chanlat, 2009, p. 28). Qualquer tentativa de reduzir o indivíduo a aspectos meramente sociológicos ou biológicos é uma tentativa de reduzir sua real dimensão e especificidade.

Em segundo lugar, Chanlat exemplifica o ser humano como um ser ativo e reflexivo. Uma das maiores características do indivíduo é pensar e agir. Os humanos aprendem, e esse aprendizado movimenta o pensamento consciente e a linguagem, o que estabelece sua singularidade enquanto espécie. Por meio dos seus atos, os indivíduos constroem sua própria realidade social, marcada por desejos e aspirações. De acordo com o autor, "o universo organizacional é um dos campos em que se pode observar ao mesmo tempo esta subjetividade em ação e esta atividade da reflexão que sustenta o mundo vivenciado da humanidade concreta" (Chanlat, 2009, p. 29).

Considerando que a realidade social pode ser concebida com a linguagem, então o ser humano também é um ser de palavra. Para o autor, a capacidade de expressar a realidade em palavras é o que leva o indivíduo a aderir ao mundo das significações.

A linguagem é um atributo indispensável para compreender o ser humano, e explorá-la no ambiente organizacional é possibilitar que se mostrem condutas e ações. Se a comunicação humana nas organizações for reduzida a uma mera transmissão de informações, o sentido e as significações são omitidos e esquece-se que toda palavra pronunciada ou escrita faz parte da esfera do agir, do fazer, do pensar e do sentimento (Grize, apud Chanlat, 2009).

Não há uma relação linear na construção dos sentidos; trata-se de um processo multirreferencial (Oliveira; Paula, C., 2008). Nessa construção, estão implicados elementos subjetivos e contextuais. De maneira ampla, discurso e linguagem são referenciados como o que participa da elaboração de enunciados nos processos comunicativos. O discurso, portanto, é o "que emerge da relação entre consciências e, sendo conformado pela linguagem, é expresso num dado contexto de interação" (Baldissera, 2008, p. 118).

Chanlat (2009) também afirma que o ser humano não pode ser reduzido a um simples receptor de estímulos, sendo, portanto, também um ser de desejo e de pulsão. É com os relacionamentos mantidos com outros indivíduos que os sujeitos veem seu anseio e sua existência legitimados ou 
não. Essa relação é o que leva os humanos a se reconhecerem, sentirem sofrimento ou prazer, realizarem ou não seus desejos e suas pulsões.

Para o autor, é preciso olhar para o ser humano tanto interna quanto externamente para que os fenômenos organizacionais sejam percebidos. Desse modo, será possível compreender o sentido que os sujeitos dão às suas ações, aos seus gestos e aos seus sentimentos.

\section{A SUBJETIVIDADE}

Compreender o conceito de subjetividade é essencial para realizar uma análise de como ela é percebida no ambiente das organizações em geral, interferindo e recebendo interferências dos relacionamentos estabelecidos entre os funcionários e, por consequência, tornando esse ambiente mais humanizado. Existem pluralidade e heterogeneidade de linguagens, espaços e práticas nos ambientes organizacionais. A subjetividade é percebida na expressão de pensamentos, condutas, emoções e ações dos protagonistas (Davel; Vergara, 2001).

Por meio das emoções - expressão da subjetividade humana - as pessoas revelam suas ações, suas preferências e seus comportamentos. "Elas são a base do processo de relação com o outro. É com base nas emoções que os agentes constituem-se como sujeitos" (Davel,Vergara, 2001, p. 229). Desse modo, o ser humano estabelece comunicação ao demonstrar suas emoções e, por consequência, sua subjetividade, na qual está compreendida a individualidade da pessoa.

A atividade humana é ampla e composta por tudo que rodeia o indivíduo -cultura, objetos, ciência, valores, hábitos, costumes, lógica e linguagens (Marchiori, 2010). Estas, por sua vez, são formadas durante a vida da pessoa e estão em constante reformulação.

Nas organizações não há controle das percepções e análises do outro, visto que se trata de algo subjetivo, pessoal. Assim, por meio dos processos interativos, os ambientes internos são espaços de interferência dos sujeitos sociais que participam dos processos, tendo papel ativo no desenvolvimento destes (Oliveira; Paula, M.A., 2010).

Dirce Backes, Valéria Lunardi e Wilson Lunardi Filho (2006b, p. 222) complementam:

A ênfase na pessoa humana do trabalhador, como uma das mais importantes vantagens competitivas de qualquer instituição, requer dos gestores o estímulo às iniciativas, a proximidade nas relações e a flexibilidade para compreender o ser humano em suas inquietações e perspectivas de vida. 


\section{A SUBJETIVIDADE NA ORGANIZAÇÃO HOSPITALAR}

O universo organizacional permite identificar a subjetividade do homem em ação, depositando ele aí seus desejos, suas aspirações e suas possibilidades de melhoria de vida. Dessa forma, percebe-se a importância do ambiente de trabalho para o reconhecimento do próprio indivíduo como ser humano. É nesse lugar que ele se socializa e lhe é possível ter uma identidade sociocultural, ou seja, todos os valores encontrados nas organizações e em seu universo social são transferidos a seus membros, usuários, clientes e fornecedores. Nesse sentido, pode-se afirmar que

a instituição hospitalar se constitui em um ambiente onde o ser humano trabalhador libera suas potencialidades e compartilha uma meta coletiva. Nesta [a instituição], as pessoas dão algo de si mesmas e esperam algo em troca. A maneira pela qual esse espaço é moldado e estruturado influencia significativamente a qualidade de vida e a satisfação dos trabalhadores. Influencia o próprio comportamento e os objetivos pessoais de cada profissional, e esse modo de ser do profissional pode afetar diretamente o modo de prestar assistência ao paciente (Backes; Lunardi; Lunardi Filho, 2006b, p. 225).

O indivíduo é por definição um "ser biopsicossocial, tríplice origem que the confere uma complexidade singular" (Morin e Ruffié, apud Chanlat, 2009, p. 35). Não se pode entender o sujeito ignorando esses três aspectos. "O biológico, o psíquico e o social contribuem, cada um a seu modo, para a edificação da ordem individual, a colocar o indivíduo enquanto indivíduo e ator de sua própria história e fixar igualmente os limites" (Chanlat, 2009, p. 35).

Quando o sujeito interage, não importa de que forma, ele está se comunicando, pois, para Gregory Bateson (apud Chanlat, 2009, p. 37), "todo comportamento é comunicação". Dessa forma, ao interagir, a pessoa expõe o que pensa, faz, gosta e deseja, ou seja, ao comunicar o que lhe vem à cabeça, o indivíduo, para Chanlat (2009), se coloca cada vez mais como pessoa, sendo ao mesmo tempo locutor, ouvinte e interlocutor.

Atualmente, é possível verificar que a eficácia da organização e sua rentabilidade são preocupações primordiais no mundo corporativo. O ser humano já não é compreendido por seus desejos e gostos, mas, segundo Chanlat (2009), ele é reduzido ao estado de engrenagem ou recurso para que a organização atinja a eficácia, entre outros objetivos.

Percebe-se, entretanto, que a obsessão pelo desempenho e pela produtividade deixa o lado humano do trabalhador em segundo plano na visão das organizações. Estas, de acordo com Chanlat (2009), mostram, uma sociedade que chegou ao individualismo em sua última instância, na qual predomina um pensamento de curto prazo e que não prioriza a transformação do trabalho em um meio de vida por estar preocupada com a acumulação da riqueza. Para Backes, Lunardi e Lunardi Filho (2006a, p. 134), a mudança desse contexto requer 
a prévia formulação de políticas organizacionais e sociais justas que considerem os seres humanos e seus direitos. Isso significa valorizar a humanidade no trabalhador, favorecendo o desenvolvimento de sua sensibilidade e competência, com mudanças nas práticas profissionais, de modo a reconhecer a singularidade dos pacientes, encontrando, junto a eles, estratégias que facilitem a compreensão e o enfrentamento do momento vivido.

Chanlat (2009) sugere que é preciso reintroduzir as pessoas no lugar que lhes pertence no universo do trabalho. É necessário rever o ponto de vista do sujeito, seus desejos e a contribuição essencial do trabalho para a construção equilibrada do seu ser, visando, no limite, à sua emancipação como sujeito. Nesse sentido, percebe-se que

os profissionais de várias áreas dos serviços hospitalares, além de competentes e continuamente atualizados nas suas respectivas áreas de conhecimento, também necessitam demonstrar, por meio de atitudes, que estão comprometidos em prestar uma assistência humanizada e hospitaleira aos clientes. Em contrapartida, a instituição de saúde tem a responsabilidade de demonstrar aos seus colaboradores que são valorizados e que é somente por meio da assistência prestada a partir de cada um deles que consegue alcançar, com sucesso, o seu objetivo (Dias, 2006, p.4).

Fica claro, desse modo, que a valorização da subjetividade do funcionário é essencial para que haja na organização hospitalar a valorização da subjetividade de todas as pessoas que a permeiam. Quando os funcionários estão satisfeitos com o ambiente em que atuam e com o trabalho que realizam, a humanização ocorre com naturalidade.

\section{ABORDAGEM CONCEITUAL DE HUMANIZAÇÃO}

O conceito semântico de humanização é: ato de humanizar. Humanizar, por sua vez, pode ser compreendido como: tornar humano, dar condição de homem, civilizar (Tetzlaff, 2011). Segundo o Dicionário Aurélio, humanizar é: elevar à altura do homem; tornar mais humano, mais sociável. Já para Jaime Betts (2003), o ato de humanizar se dá quando o sujeito faz o reconhecimento do outro por meio da linguagem.

Tratando-se de organizações, o termo pode assumir significados distintos, dependendo de sua aplicação. A humanização em relação ao ambiente externo diz respeito aos projetos socialmente responsáveis; já a humanização do ambiente interno se relaciona com a emancipação dos funcionários como seres humanos inseridos no meio organizacional. 
Para Sylvia C. Vergara e Paulo C. Branco (2001, p. 22) uma empresa humanizada é

aquela que, voltada para seus funcionários e/ou para o ambiente, agrega outros valores que não somente a maximização do retorno para os acionistas. Realiza ações que, no âmbito interno, promovem a melhoria da qualidade de vida e de trabalho, visam à construção de relações mais democráticas e justas, mitigam as desigualdades e diferenças de raça, sexo ou credo, além de contribuírem para o desenvolvimento das pessoas sob os aspectos físico, emocional, intelectual e espiritual.

Gregória Baremblitt (2006) considera que a humanização pode ser entendida por: necessidades básicas de qualquer indivíduo, como alimentação, moradia, vestuário, educação, segurança, justiça, trabalho, acesso à liberdade de associação, de pensamento e de expressão, de ir e vir, de prática política, científica, arte, esporte, tempo livre, culto religioso e o cuidado da saúde. Ou seja, o conjunto de variadas características que faz o indivíduo ser visto como um ser humano, compreendido não como aquele que é pago para fazer o trabalho ou para pensar e agir conforme determinado pela organização, mas, sobretudo, um sujeito dotado de personalidade e subjetividade, capaz de entender sua posição como funcionário e assim desenvolver sua auto-crítica.

Nessa perspectiva e sob o aspecto de emancipação, percebe-se que "humanizar significa respeitar o trabalhador enquanto pessoa, enquanto ser humano. Significa valorizá-lo em razão da dignidade que lhe é intrínseca" (Costa, 2004, p. 17).

\section{HUMANIZAÇÃO NA ORGANIZAÇÃO HOSPITALAR}

Para que a humanização ocorra, não é necessário o indivíduo ter conhecimento técnico somente, mas esta relaciona-se à maneira com o qual esse conhecimento é utilizado. No caso das organizações hospitalares, está vinculada à forma com que os pacientes são tratados e à qualidade do ambiente de trabalho. Backer, Lunardi e Lunardi Filho (2006b, p. 222) explicam que, um hospital humanizado com atendimento de qualidade "é aquele que contempla, em sua estrutura física, tecnológica, humana e administrativa, a valoração e o respeito à dignidade da pessoa humana, seja ela paciente, familiar ou o próprio profissional que nele trabalha".

Assim, devem ser valorizados todos os indivíduos que compõem esse cenário, havendo uma dimensão humana nas relações profissionais. É imprescindível que os funcionários que trabalham nessa organização sejam, portanto, tratados de forma humana. Backer,Lunardi e Lunardi Filho (2006b, p. 222) expõem:

Tendo como pressuposto que a humanização da assistência emergirá com a realização pessoal e profissional dos que a fazem, desenvolver um processo de humanização, inicialmente com 
ênfase no trabalhador, demanda, principalmente, por parte dos dirigentes, acolhimento, escuta e uma atitude de sensibilidade, para compreender a realidade que se apresenta na perspectiva do próprio trabalhador, seja ela favorável ou não. É preciso, assim, estimular o trabalhador a participar ativamente do processo de construção de uma proposta de humanização, ou seja, é preciso auxiliá-lo a tomar consciência da realidade, do seu estado existencial e de sua própria capacidade para transformá-la. Em outras palavras, não podemos limitar o entendimento de um atendimento humanizado como uma prática imposta, que deveria se dar de maneira vertical e fragmentada. Diferentemente, um processo de humanização do ambiente institucional pressupõe um processo participativo e dinâmico, não excludente, baseado em relações horizontais e dialógicas. O profissional da saúde, ao refletir sobre as condições e relações de trabalho e o seu modo de agir, pode inserir-se na realidade de uma maneira mais crítica e consciente. Problematizar e concretizar a humanização do ambiente, mais especificamente a partir do trabalhador, implica uma reflexão crítica e dialógica acerca dos princípios e valores que norteiam a prática dos profissionais, de modo a assumirem sua condição de sujeitos e agentes de transformação.

Percebe-se que, à medida que o profissional é valorizado, reconhece a importância de sua subjetividade, de sua individualidade, transfere esse conhecimento ao cuidar dos seus pacientes, valorizando-os, constituindo um processo de humanização (Backes; Lunardi; Lunardi Filho, 2006b). A humanização é, assim, uma nova visão de atendimento que envolve a todos da organização hospitalar. A cultura dessa organização precisa, então, dar espaço às manifestações dos pensamentos dos funcionários, buscar a participação dos envolvidos no sentido de estimular a construção de estratégias humanas e a horizontalidade nas relações. Backes, Lunardi e Lunardi Filho (2006b, p. 222) afirmam também que

produzir conhecimentos acerca da humanização nas instituições de saúde pressupõe, nesse contexto, estabelecer um processo educativo dinâmico, criativo, participativo e sistemático, a fim de que os trabalhadores assumam efetivamente o seu papel de sujeitos da produção. (...) São os profissionais, através do seu trabalho e das relações que estabelecem, que determinam e retratam se o atendimento ao usuário é ou não é humanizado. Todo processo de humanização, para ser efetivo e transformador, necessita estreitar os laços de comunicação, na tentativa de desvendar e respeitar a leitura de mundo dos trabalhadores, favorecendo a compreensão contínua da realidade.

Há a necessidade de uma comunicação efetiva, que permeie funcionários e pacientes, em prol de uma saúde digna para todos, em que exista a valorização dos envolvidos como seres humanos dotados de subjetividade e capacidade crítica. A respeito da humanização no atendimento hospitalar, Dias (2006, p. 3) completa: 
A humanização do atendimento hospitalar requer mudança de valores, comportamento, conceitos e práticas, exigindo do atendente um reposicionamento no que se refere ao atendimento aos usuários. (...) O cliente hospitalado é um ser único, que está num momento de vulnerabilidade, pois o seu bem maior - a vida - pode estar ameaçado. Esse cliente requer uma assistência única e humanizada, além de competente no aspecto técnico-científico (Dias, 2006, p. 3).

\section{COMUNICAÇÃO E HUMANIZAÇÃO}

A comunicação nos ambientes internos organizacionais não é somente informacional. O público interno é ativo nesse processo comunicativo, sendo visualizado como ator, pois "todo sujeito é ao mesmo tempo produtor e receptor de discursos e a própria interação implica uma relação de substituição entre instâncias" (Oliveira; Paula, C. C., 2008, p. 97).

Por serem compostas por várias pessoas e cada indivíduo ter anseios e expectativas distintas, as organizações são vistas como organismos vivos, dotadas de complexidade (Marchiori, 2009). A comunicação, além de ser atividade central, assume dimensão formativa, constitutiva da realidade, estando vinculada à humanização desses ambientes organizacionais.

Dessa maneira, pode-se afirmar que "a comunicação é o processo por meio do qual um ambiente comum é criado e a partir de onde os interlocutores produzem sentido" (Baldissera, 2008, p. 114). Nas organizações, há múltiplas interações entre os protagonistas, conforme os contextos apresentados. Nessas relações a organização é definida, por meio de seus atores sociais.

Segundo o paradigma relacional, a dimensão simbólica da comunicação está materializada nos discursos dos interlocutores - enunciados e marcas de enunciação -, que, como vestígios da comunicação, trazem impressas marcas do contexto em que a interação se dá, características dos interlocutores e da própria relação. Discursos e linguagem são entendidos, aqui, de maneira ampliada, como tudo que possa participar da construção de enunciados nos processos comunicativos. O discurso é, assim, entendido como o que emerge da relação entre consciências e, sendo conformado pela linguagem, é expresso num dado contexto de interação (Baldissera, 2008, p. 118).

Nas organizações contemporâneas, desenvolvem-se não somente as capacidades profissionais dos indivíduos, mas também as pessoais, pois eles se relacionam a todo o momento. Marchiori (2010, p. 143) afirma que "o lugar da comunicação nas empresas humanizadas é o lugar da fala, da interação e do conhecimento", levando as pessoas ao desenvolvimento humano. A autora compreende que, assim como a comunicação é algo natural na organização, a humanização também o é. Richard Hall (2004) acredita que a comunicação se torna mais importante à medida que uma organização é orientada para as pessoas e para as ideias. O processo da comunicação também é entendido como relacional, sendo que a imagem que o receptor tem do comunicador é essencial para a interpretação da comunicação. Inesita S. Araújo (2007, p. 119) ressalta: 
A comunicação, dentro desse raciocínio, é aquela que, ao invés de dar importância apenas às falas tradicionalmente autorizadas, como as das instituições e dos serviços/equipes de saúde, reconhece a existência da polifonia social, da possibilidade de acolher e ampliar as muitas vozes com os muitos sentidos possíveis. É também uma comunicação que entende que os saberes da saúde não se produzem apenas a partir do saber técnico-científico e por uma dimensão apenas cognitiva, e sim por meio da articulação de práticas, saberes, memórias, expectativas, emoções, lugares de fala etc., constituídos pelas vozes que emanam das instituições e da população.

De acordo com Linda Putnam, Nelson Phillips e Pamela Chapman (2009, p. 78) "as organizações não são simples contêineres ou recipientes nos quais as atividades de comunicação ocorrem; antes, a comunicação e a organização podem produzir-se uma à outra".

Para que ocorra a humanização, é necessário que haja troca de experiências e conhecimentos, e isso só é possível por meio da comunicação. Tetzlaff $(2010$, p. 2) expõe:

Abordar a humanização é analisar a própria evolução humana, enfatizar a ética e o relacionamento interpessoal; não se descartou o tema, [ele] apenas possibilitou mais espaços para avanços de outras áreas e/ou assuntos de interesses para o desenvolvimento técnico científico, protelando as questões de relacionamentos humanos. Possibilitar a intersecção entre a ética, o respeito, dignidade, individualismo entre indivíduos promove a humanização. Portanto, vale ressaltar que mesmo a sociedade valorizando o poder capitalista para sua sobrevivência, seja em qualquer campo dos negócios públicos ou privados, a questão sempre voltará para a qualidade da coletividade, tendo o ser humano como foco principal e riqueza de uma sociedade.

Assim, um conceito importante para o melhor entendimento do objetivo deste artigo é o de "relacionamento". Fábio França (2009), no capítulo intitulado "Gestão de relacionamentos corporativos", afirma que, comumente, ele está ligado à capacidade de convivência, de estabelecer vínculos oficiais, com objetivos definidos, permanentemente ou não. Já a palavra latina corpus - corpo, ajuntamento, corporação - é o termo referencial para corporativo. Os relacionamentos corporativos, portanto, estão vinculados à organização como corpo, sistema orgânico de partes que interagem, movidas por objetivos e interesses.

Para configurar os relacionamentos corporativos é necessário lembrar que eles provêm das e se ligam diretamente a diretrizes organizacionais, tais como visão, missão, objetivos, valores, cultura e estratégias de curto, médio e longo prazo. A gestão dos relacionamentos da organização com seus públicos tem como objetivo específico fazer com que ela obtenha sucesso na execução de suas diretrizes (França, 2009, p. 222). 
Assim, percebe-se que "o grau de relacionamento corporativo determina o grau de comprometimento da empresa com seus públicos e vice-versa" (França, 2009, p. 224). Nesse sentido, faz-se necessário que o relacionamento com o público interno leve em conta a subjetividade e os anseios das pessoas envolvidas, ou continuarão a, unicamente, reproduzir, por meio de um discurso com o objetivo falacioso de inclusão, os interesses da organização, desconsiderando o potencial de emancipação dos sujeitos envolvidos.

\section{O PROJETO HUMANIZASUS}

No Brasil, existe desde 2003 uma política de humanização na saúde pública, o HumanizaSUS. Esse projeto se consiste na valorização da gestão da comunicação enquanto uma dimensão de contínua valorização das condições humanas e emancipatórias dos indivíduos envolvidos nos processos do sistema de saúde público brasileiro. Ao compreender que a comunicação e o estabelecimento de relacionamentos saudáveis são fatores relevantes no escopo humanizador de organizações, as unidades do sus têm, com esse programa, um aliado na melhoria das relações de trabalho e, consequentemente, um desenvolvimento amplo do atendimento de saúde no país.

Em sua própria definição, o projeto afirma que ele "estimula a comunicação entre gestores, trabalhadores e usuários para construir processos coletivos de enfrentamento de relações de poder, trabalho e afeto" (Brasil, 2011). Essas situações muitas vezes "produzem atitudes e práticas desumanizadoras que inibem a autonomia e a corresponsabilidade dos profissionais de saúde em seu trabalho e dos usuários no cuidado de si" (Brasil, 2011).

Algumas inovações utilizadas são: valorização dos diferentes sujeitos implicados no processo de produção de saúde - usuários, trabalhadores e gestores; estabelecimento de vínculos solidários e de participação coletiva no processo de gestão; luta por um SUS mais humano, porque construído com a participação de todos e comprometido com a qualidade dos seus serviços e com a saúde integral para todos e qualquer um.

Entre seus princípios, percebe-se a utilização da comunicação para que as relações de trabalho sejam menos hierarquizadas e para que haja troca de conhecimento, diminuindo o isolamento. Todas as pessoas têm sua responsabilidade como cidadãs e assumem seus papéis. É um método de inclusão de trabalhadores, usuários e gestores. A humanização ocorre na participação e no envolvimento, para que todos sejam agentes ativos nesse contexto. Dessa forma, processos de trabalho são reinventados e há a cogestão e corresponsabilidade no que diz respeito à saúde. Assim, percebe-se que a comunicação é elemento-chave nesse processo.

De maneira especial, o projeto apresenta alguns valores-chave para que tenha êxito em todo o território nacional: a transversalidade e o protagonismo. Tais dimensões têm como papel central a diluição de processos identitários nas relações de trabalho muito hierarquizadas e promovem a real emancipação do sujeito, uma vez que se trata de ações que o valorizem como cidadão e funcionário. Interessante ainda ressaltar que todo esse plano de humanização e valorização 
acontece em ambiente interno, o que reforça a construção de uma identidade organizacional e projeta a imagem do Sistema Único de Saúde do Brasil.

\section{CONSIDERAÇÕES FINAIS}

É imprescindível o estudo a respeito do ser humano ao abordarmos a humanização, pois, além de locutor e interlocutor, o indivíduo é agente central nesse processo. Assim, a humanização do ambiente hospitalar deve ser pautada no trabalhador, pois, afinal, como exigir um atendimento humanizado aos pacientes se os próprios funcionários carecem dessa compreensão?

O ser humano é multifacetado, não devendo ser referenciado só de maneira genérica. Muitas vezes, o tratamento que recebe, mesmo como funcionário de organizações hospitalares, o reduz a uma dimensão simplista, na qual a sua subjetividade não é levada em consideração. Nesse caso, o seu lado humano fica em segundo plano, já que ele não é visto como um sujeito complexo, mas sim como peça para a geração de resultados e lucros na organização em que trabalha. Esse processo de acomodação e sujeição do indivíduo, que a priori já se configura como uma agressão à sua saúde mental, potencializa um ambiente de trabalho pouco humanizado e carente de subjetividades expostas.

A comunicação é a forma que o ser humano encontra como ferramenta para se colocar como pessoa/indivíduo, dotado de subjetividade, no local em que atua, à medida que é ouvinte, emissor e mediador. Com ela os sentidos são criados e recriados, já que ela não é algo constante, mas sim, mutável. É dessa maneira que, com sua dimensão formadora da realidade, a comunicação se vincula à humanização dos ambientes organizacionais, tornando-a possível e estabelecendo processos educativos e emancipatórios. Percebe-se, então, que a comunicação defendida neste artigo, principalmente uma comunicação de perspectiva relacional, vai além dos discursos organizacionais, pois se refere à possibilidade de o trabalhador expressar-se, emancipando-se como sujeito autônomo.

Fica claro que o conhecimento teórico-prático é importante, mas não é suficiente. Portanto, instigar essa visão crítica no trabalhador e auxiliá-lo a atuar de forma a proporcionar um ambiente saudável de trabalho faz-se indispensável para que ocorra a humanização. Afinal, à medida que os funcionários da organização hospitalar são valorizados, com sua individualidade e sua subjetividade, essa mesma valorização é transferida no cuidado e na abordagem com os pacientes, constituindo um real ciclo de humanização.

O projeto HumanizaSUS, nesse contexto conflituoso, deflagra um movimento incipiente de humanização dos ambientes de trabalho, com específica incidência nos hospitais e nas organizações do sistema de saúde público brasileiro, com a intenção de humanizar a estrutura de atendimento à demanda de saúde coletiva, por meio dos relacionamentos, e proporcionar a esses ambientes, marcados pela falta de estrutura e condições dignas de atendimento e trabalho, uma conjuntura emancipatória e educativa. 


\section{REFERÊNCIAS}

ARAUJO, Inesita Soares. Comunicação esSaúde: de comunicação todo mundo entende. In: MARTINS, Carla Macedo; STAUFFER, Anakeila de Barros. Educação e saúde. Rio de Janeiro: EPSJV / Fiocruz, 2007.

BACKES, Dirce Stein; LUNARDI, Valéria Lerch; LUNARDI FILHO, Wilson D. A humanização hospitalar como expressão da ética. Revista Latino-Americana de Enfermagem, Ribeirão Preto (SP), v. 14, n. 1, p. 132-135, jan.-fev $2006 a$.

O processo de humanização do ambiente hospitalar centrado no trabalhador. Revista da Escola de Enfermagem USP, São Paulo, v. 40, n. 2, p. 221-227, 2006b.

BALDISSERA, Rudimar. Comunicação organizacional: a democrática opção pelo dialogismo e pela recursividade. In: MOREIRA, Elizabeth Huber; PONS, Mônica (Org.). Perspectivas em relações públicas. Santa Cruz do Sul (RS): Edunisc, 2008.

BAREMBLITT, Gregório. Que se entende por humanidade e humanização? Portal Humaniza, 2006. Disponível em: <http:// www.portalhumaniza.org.br/ph/texto.asp?id=46>. Acesso em: 04 jun. 2011.

BETTS, Jaime. Considerações sobre o que é o humano e o que é humanizar. Portal Humaniza, 2003. Disponível em: <http:// www.portalhumaniza.org.br/ph/texto.asp?id=37>. Acesso em: 04 jun. 2011.

BRASIL. Ministério da Saúde. Política nacional de humanização. Disponível em: <http://portal.saude.gov.br/portal/saude/ cidadao/area.cfm?id_area=1342>. Acesso em: 15 fev. 2011.

CHANLAT, Jean-François. O indivíduo na organização: dimensões esquecidas. Vol. 1. São Paulo: Atlas, 2009.

COSTA, Welington Soares da. Humanização, relacionamento interpessoal e ética. Caderno de Pesquisas em Administração, São Paulo, v. 11, n. 1, p. 17-21, jan.-mar. 2004.

DAVEL, Eduardo; VERGARA, Sylvia Constant (Org.). Gestão com pessoas e subjetividade. São Paulo: Atlas, 2001.

DIAS, Maria A. de Andrade. Humanização do espaço hospitalar: uma responsabilidade compartilhada. O mundo da saúde, São Paulo, v. 30, n. 2, p. 340-343, abr.-jun., 2006.

FRANÇA, Fábio. Gestão de relacionamentos corporativos. In: GRUNIG, James E.; FERRARI, Maria Aparecida; FRANÇA, Fábio.. Relações públicas: teoria, contexto e relacionamentos. São Caetano do Sul (SP): Difusão, 2009.

HALL, Richard. Organização: estruturas, processos e resultados. 8. ed. São Paulo: Prentice Hall, 2004.

MARCHIORI, Marlene. O grande ator nas organizações: o ser humano. São Paulo, 2009. Disponível em: <http://aberje.com. br/acervo_colunas_ver.asp? ID_COLUNA=69\&ID_COLUNISTA=43>. Acesso em: 17 abr. 2011. 
. Comunicação como expressão da humanização nas organizações da contemporaneidade. In: KUNSCH, Margarida M. Krohling (Org.). A comunicação como fator de humanização das organizações. São Caetano do Sul (SP): Difusão, 2010, p. 139-148.

OLIVEIRA, Ivone de Lourdes; PAULA, Carine F. Caetano. Comunicação no contexto das organizações: produtora ou ordenadora de sentidos? In: OLIVEIRA, Ivone de Lourdes; SOARES, Ana Thereza Nogueira (Org.). Interfaces e tendências da comunicação no contexto das organizações. São Caetano do Sul (SP): Difusão, 2008.

OLIVEIRA, Ivone de Lourdes; PAULA, Maria Aparecida de. Interações no ambiente interno das organizações: implicações da complexibilidade. In: MARCHIORI, Marlene (Org.). Comunicação e organização: reflexões, processos e práticas. São Caetano do Sul (SP): Difusão, 2010.

PUTNAM, Linda L.; PHILLIPS, Nelson; CHAPMAN, Pamela. Metáforas da comunicação e da organização. In: CLEGG, Stewart; HARDY, Cynthia; NORD, Walter R. Handbook de estudos organizacionais. Vol 3. São Paulo: Atlas, 2009.

TETZLAFF, Alessandra Andrea da Silva. O que é humanização? Curitiba, Hi Technologies, 2011. Disponível em: <http:// hitechnologies.com.br/ humanizacao/o-que-e-humanizacao/>. Acesso em: 15 maio 2011.

VERGARA, Sylvia Constant; BRANCO, Paulo Durval. Empresa humanizada: a organização necessária e possível. RAE Revista de Administração de Empresas, São Paulo, FGV, v. 41, n. 2, p. 20-30, abr.-jun. 2001.

Recebido em: 04.03.2012 / Aceito em: 04.06.2012 